\title{
Effect of Wind Load on Performance of Photovoltaic (PV) Modules Available in Pakistan
}

\author{
Rizwan Mehmood Gul'a , Fahad Ullah Zafar ${ }^{2 a}$, Muhammad Ali Kamran ${ }^{1 b}$, \\ Muhammad Noman ${ }^{2 b}$
}

RECEIVED ON 07.01.2019, ACCEPTED ON 19.05.2020

\begin{abstract}
Mechanical integrity of a Photovoltaic (PV) module plays a major role in its performance and electrical output. Mechanical loads which include loads produced by wind, snow, rain, and hail tend to degrade the performance of PV module by generating stresses and enhancing micro-cracks and defects. This research aims to investigate the impact of wind loads on the performance of PV modules, particularly the degradation in its power output. A load of 2400 Pa was applied as per international standards (ASTM E1830-15 and IEC-61215). A total of four PV module samples, of the same specifications with $60 \mathrm{~W}$ rated power, were initially subjected to solar flash testing and Electroluminescence (EL) imaging. This was followed by three cycles of mechanical load test. After the mechanical load tests, the modules were again subjected to solar flash testing and EL imaging and the results were compared. It was noted that static wind load degrades the mechanical integrity of photovoltaic modules in two ways; by aiding the propagation of existing cracks and initiating new cracks. This loss of mechanical integrity degraded the power output of PV module. Maximum drop of $2 \%$ in the power output and $0.27 \%$ in the efficiency was observed. In addition, the average increase of $3.37 \%$ in the series resistance was observed indicating decrease in performance.
\end{abstract}

Keywords: Mechanical Integrity, Photovoltaic Modules, Wind Load, Electrical Efficiency.

\section{INTRODUCTION}

$\mathrm{W}$

ith the rapid depletion of fossil fuels, a paradigm shift to renewables has been observed in recent years. Exhaustible petroleum resources and fossil fuels along with their ill-effects on environment are the reasons of the paradigm shift of energy. Extensive research is being carried out to explore sustainable and eco-friendly resources of energy. In this scenario, renewable energy resources provide the most appropriate solution to the problem. Much progress has been made in the efforts, focused mainly towards harnessing energy by water, wind, sun, and various other energy banks. Solar energy is a renewable energy source which is substantial and whose utilization is economically sustainable. Photovoltaics (PV) are most widely used system for harnessing solar energy $[1,2]$.

PV technology can generate energy for a broad range of applications. During their lifetime, PV modules are exposed to different climatic conditions like wind, snow, rain, hail, temperature fluctuations, humidity, and dust. All these factors contribute to the degradation in their performance. Some of these factors like wind, snow and hail impose mechanical loads on the modules. Static wind; wind blowing with a constant speed, impose static loads on the front and back surfaces of PV modules. Long term exposure to these winds result in breaking of the cell

${ }^{1}$ Department of Mechanical Engineering, University of Engineering and Technology, Peshawar, Pakistan. Email: ${ }^{2}$ rgul@uetpeshawar.edu.pk (Corresponding Author), balikamran@uetpeshawar.edu.pk

${ }^{2}$ US-Pakistan Center for Advanced Studies in Energy, University of Engineering and Technology, Peshawar,

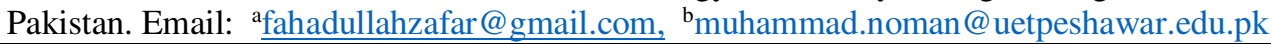

This is an open access article published by Mehran University of Engineering and Technology, Jamshoro under CC BY 4.0 International License. 
interconnections, cracking of the glass, future of the solder joints and breaking of the cells (themselves). The separation in the cells are the main reason for the degradation in performance parameters like the output power, cell efficiency, series and parallel resistances, fill factor, peak current and peak voltages [3-6].

Stresses are induced in the modules during fabrication. These stresses generate micro-cracks in the modules. The mechanical loadings further induce stresses in the modules and generate new cracks as well as propagate the existing cracks. These cracks provide resistance to flow of electric current and reduce output power of the modules. Moreover, if a crack gets initiated and propagates along the width of the cell, it can isolate the active cell area thus causing a significant drop in the power output and efficiency. While if a crack does not propagate in the cell, it may not cause isolation of the active cell area and does not influence the output power [7-10].

This research aims to investigate the impact of wind loads on the performance of mono-crystalline PV modules. Four samples from the same vendor were subjected to identical loading conditions as imposed by static wind using the ASTM E1830-15 standard. The pre- and post-testing data obtained by electroluminescence imaging and solar flash testing was compared and analyzed.

\section{MATERIALS AND METHODS}

Four commercially available silicon based monocrystalline PV modules (German Cells, PRC), each having rated power of $60 \mathrm{~W}$ were bought from a local vendor. The construction of the modules was: Glass/EVA/Si-cell/EVA/Tedlar (Fig. 1a). The glass in the modules was the commonly used tempered glass for the PV modules of standard thickness $(3.2 \mathrm{~mm})$. Ethylene vinyl acetate (EVA) was used as encapsulant, while tedlar acted as the back sheet. Each sample was a 36-cell module, having dimensions of $750 \times 535 \mathrm{~mm}$, while the dimensions of solar cells were $55 \times 156 \mathrm{~mm}$ with chamfer of $15 \mathrm{~mm}$ (along the width) for the corner cells. The laminate was supported by an aluminum frame. Table 1 lists rated specifications of the modules. Electroluminescence imaging and solar flash testing of the modules was

\begin{tabular}{|c|c|c|}
\hline $\begin{array}{l}\text { S. } \\
\text { No. }\end{array}$ & Parameter & Value \\
\hline 1 & $\begin{array}{l}\text { Maximum power }\left(\mathrm{P}_{\max }\right) \text { at } \\
\text { standard testing condition }\end{array}$ & $60 \mathrm{~W}$ \\
\hline 2 & $\begin{array}{l}\text { Tolerance in the output } \\
\text { parameters }\end{array}$ & $\pm 3 \%$ \\
\hline 3 & Open circuit voltage $\left(\mathrm{V}_{\mathrm{oc}}\right)$ & $21.6 \mathrm{~V}$ \\
\hline 4 & Short circuit current $\left(I_{\mathrm{sc}}\right)$ & $4.04 \mathrm{~A}$ \\
\hline 5 & $\begin{array}{l}\text { Voltage at maximum power } \\
\left(\mathrm{Vp}_{\max }\right)\end{array}$ & $17.8 \mathrm{~V}$ \\
\hline 6 & $\begin{array}{l}\text { Current at maximum power } \\
\left(I p_{\max }\right)\end{array}$ & $3.37 \mathrm{~A}$ \\
\hline 7 & Maximum series fuse rating & $12 \mathrm{~A}$ \\
\hline 8 & Dimension $(\mathrm{L} x \mathrm{~W} \times \mathrm{t})$ & $\begin{array}{c}750 \mathrm{~mm} \mathrm{x} \\
535 \mathrm{~mm} \mathrm{x} \\
20 \mathrm{~mm}\end{array}$ \\
\hline 9 & $\begin{array}{l}\text { Nominal Operating Cell } \\
\text { Temperature (NOCT) }\end{array}$ & $45^{\circ} \mathrm{C}$ \\
\hline
\end{tabular}

carried out prior to and after the application of load at Pakistan Council of Renewable Energy Technologies (PCRET), Islamabad, Pakistan. The data obtained from these tests was analyzed for mechanical degradation and subsequent drop in electrical power output.

Electroluminescence (EL) testing was performed using an electroluminescence tester manufactured by Wuhan Gobo Photoelectric, PRC (Model: GEL-610). In this technique, the PV module acts as a forward biased diode. Potential difference is applied across its terminals which causes the electron hole recombination and produces the electroluminescence (EL) effect. An infra-red CCD camera is used to detect the image as the rays emitted by the module are in the infra-red region. Any crack present in the cells can be seen in the image as the input current is unable to overcome the resistant offered by the cracked regions and cause the luminescence effect. Thus, the regions appear darker in the EL image [11].

Solar flash testing was performed using a AAA class Sun Simulator (Model: GSMT-H-3A by Wuhan Gobo Photoelectric, PRC). The test measures electrical parameters of the module like peak output power, efficiency, open circuit voltage, series resistance, short circuit current and fill factor. Xenon arc lamp is used in this test as the spectrum generated (produced) by this lamp matches with (or is close to) the solar 
spectrum. Standard Test Conditions (STC) which corresponds to; cell temperature $25^{\circ} \mathrm{C}$, Irradiance $1000 \mathrm{~W} / \mathrm{m}^{2}$, spectral distribution of irradiance AM 1.5 were used [12].

An experimental setup was fabricated in this study as per ASTM Standard E1830-15, shown in Fig. 1(b). Sand bag having dimensions $30 \times 21 \times 7$ inch was used to apply a load of $2400 \mathrm{~Pa}$ successively on the front and back surfaces of the modules. Fine grain sand was used which was uniformly distributed in the bag. The dimensions of the bag were according to the size of the module. The mechanical load test was performed according to the international standards (ASTM E1830-15 and IEC-61215) [13, 14]. According to these standards three cycles of $2400 \mathrm{~Pa}$ pressure are to be applied on the module in such a way that each cycle consists of two halves. For the first half of the cycle, load is applied on the front side of the module while for the remaining half, load is applied on the back side. The total duration of one cycle is two hours.

\section{RESULTS}

Fig. 2 shows the results obtained by EL testing of Module 1. Various defects were observed in module 1 before the application of mechanical load (Fig. 2 (a)).

These defects include cracks (region 1), tire like

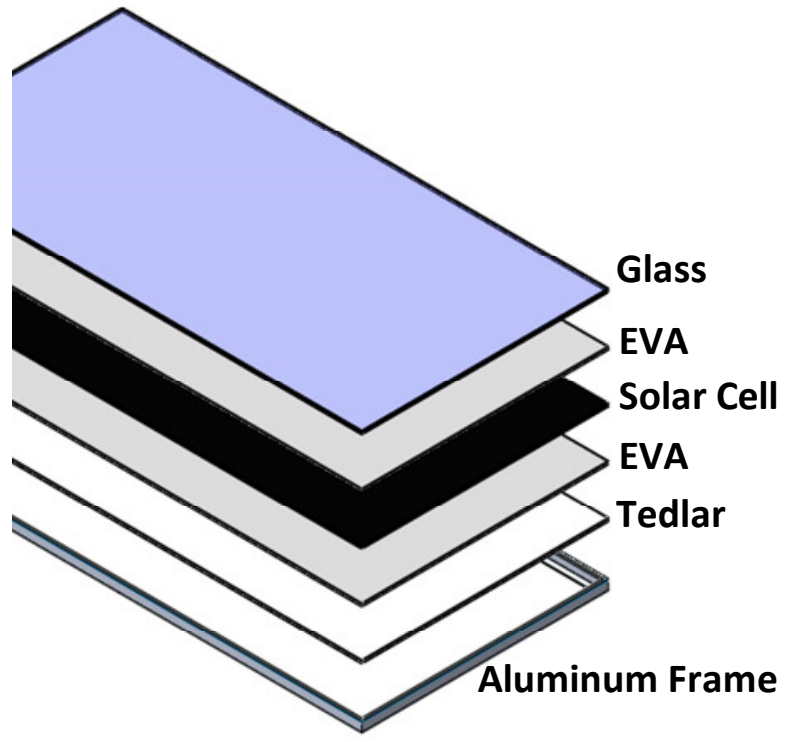

(a) patterns (region 2), completely dark regions (region 3) and lightly shaded regions (region 4 and 5). The EL image of the module after the mechanical testing (Fig. 2 (b)) shows that cracks (a-e) were generated in the cells due to the application of load. An important observation about these cracks was their orientation with respect to the cell geometry. Most of the new cracks were diagonal to bus bars. In the EL images of this module, minor difference in the pixels is observed in areas of existence of cracks. One of the cracks generated during the mechanical load test even manages to propagate, moving over the bus-bar resulting in a relatively darker region in the vicinity (region e).

Module 2 was in good condition before the application of mechanical load as it did not have any major defect (Fig. 3). As compared to module 1, very few cracks were found in this module after the application of load. The cracks observed run diagonally to the bus bars but are not strong enough to cross the bus bars.

No defects were visible in module 3 prior to testing (Fig. 4 (a)). However, a glance of Fig. 4 (b) reveals that mechanical loads induced diagonal cracks in this module as well. These cracks did not cause electrical isolation of the cells.

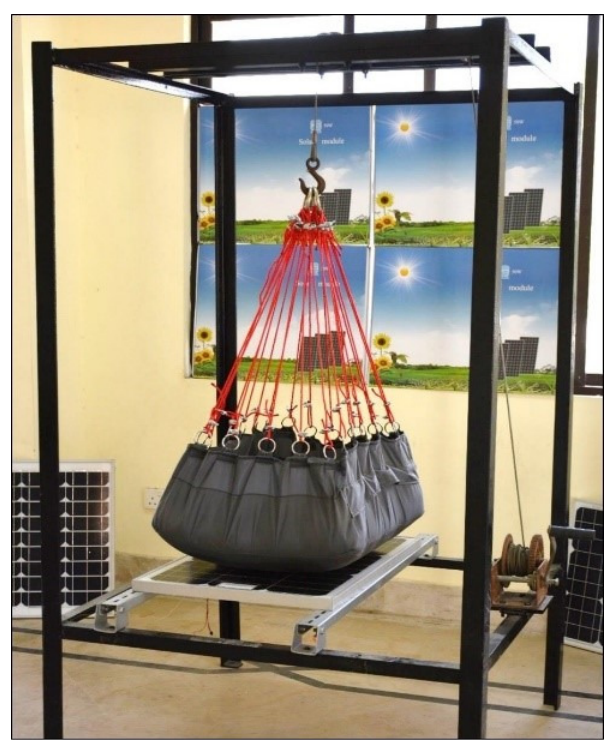

(b)

Fig. 1: (a) Structure of PV modules (b) Setup used for mechanical testing of modules 


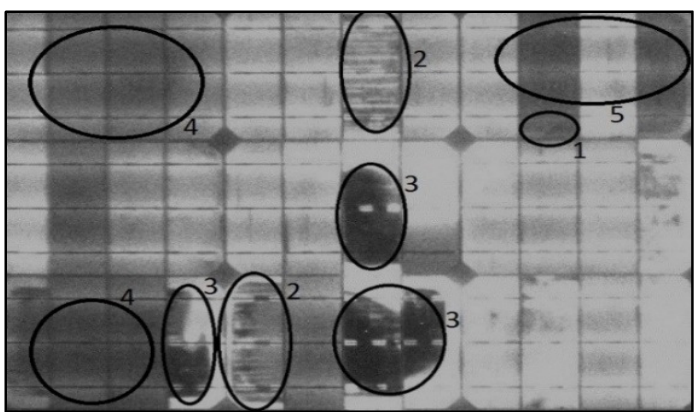

(a)

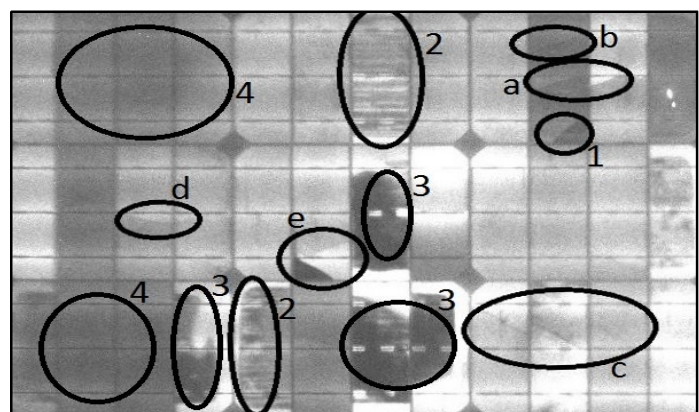

(b)

Fig. 2: Electroluminescence images of module 1: (a) before mechanical test and (b) after mechanical test

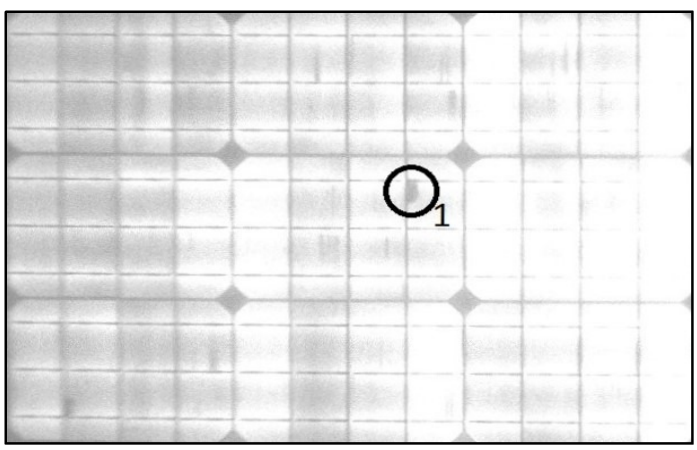

(a)

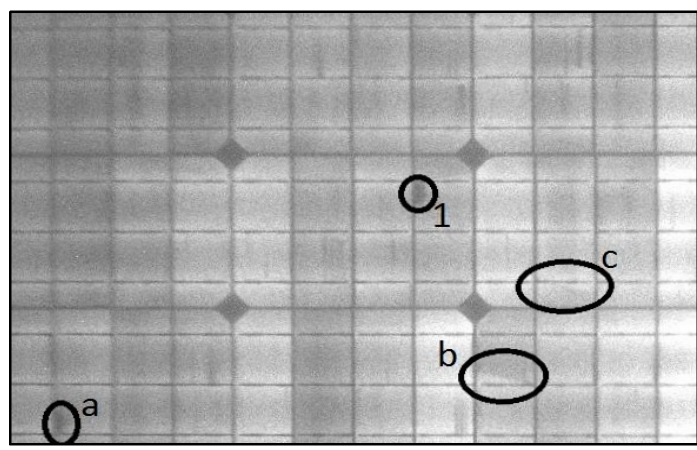

(b)

Fig. 3: Electroluminescence images of module 2: (a) before mechanical test and (b) after mechanical test

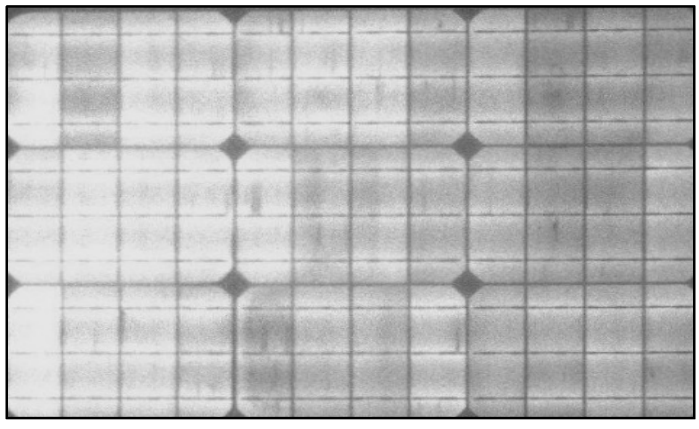

(a)

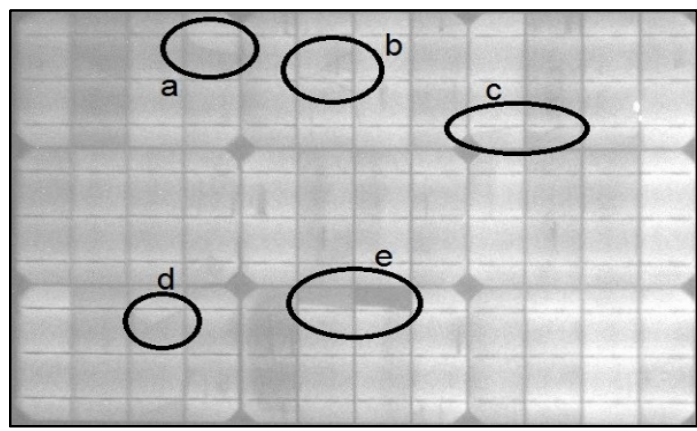

(b)

Fig. 4: Electroluminescence images of module 3: (a) before mechanical test and (b) after mechanical test

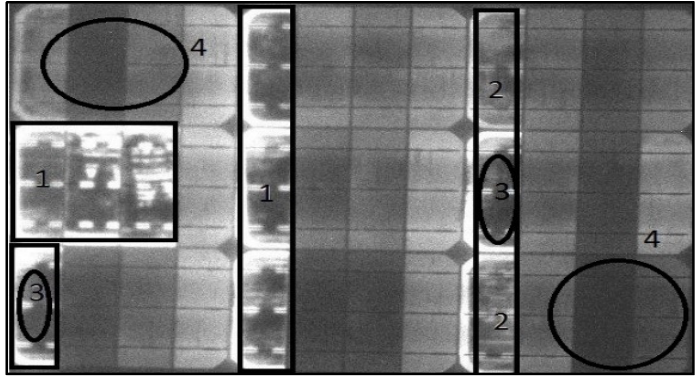

(a)

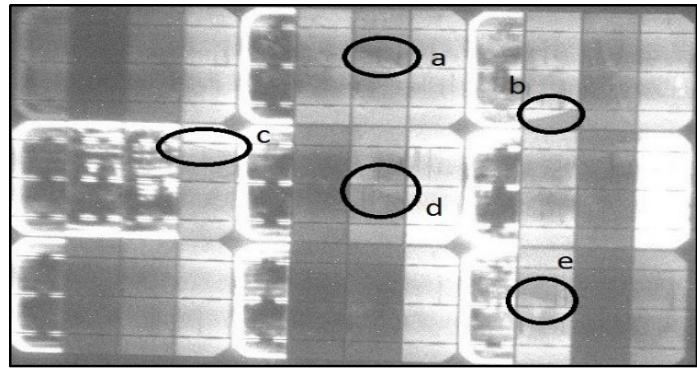

(b)

Fig. 5: Electroluminescence images of module 4: (a) before mechanical test and (b) after mechanical test Mehran University Research Journal of Engineering and Technology, Vol. 40, No. 4, October 2021 [p-ISSN: 0254-7821, e-ISSN: 2413-7219] 
The EL image of module 4 shows that it has several of pre-loading defects, which include manufacturing defects, and defects due to transportation and handling as shown in Fig. 5(a). The brighter regions observed in this image are the areas of doping mismatches as visible in region ' 1 ' and ' 2 '. The region ' 3 ' shows the areas that are electrically isolated and that is why they appear dark in the EL image. While region '4' show the shaded areas.

Fig. 5(b) shows the post-loading EL image of the Module 4. Cracks resulting from mechanical loadings can be seen in the image. A minor difference in the color can be seen in areas of existence of cracks. These cracks were oriented diagonally and did not cause electrical isolation of the cells.

Three important electrical parameters obtained from solar flash testing namely peak output power, electrical efficiency, and series resistance were analyzed. The results are shown in table 2 . The results show that module 1 had the maximum drop in efficiency and peak power, whereas no change of these parameters was noted for modules 2 and 4. Module 1 showed the highest increase of $4.88 \%$ in the series resistance while the lowest increase was seen in module 4 (2.73\%).

\begin{tabular}{|c|c|c|c|}
\hline \multicolumn{4}{|c|}{$\begin{array}{c}\text { Table 2: Changes in electrical performance of the } \\
\text { modules as obtained from solar flash testing }\end{array}$} \\
\hline S. No. & $\begin{array}{c}\text { Percent } \\
\text { drop in } \\
\text { peak } \\
\text { output } \\
\text { power }\end{array}$ & $\begin{array}{c}\text { Percent } \\
\text { drop in } \\
\text { efficiency }\end{array}$ & $\begin{array}{c}\text { Percent } \\
\text { increase } \\
\text { in series } \\
\text { resistance }\end{array}$ \\
\hline Module 1 & 2.23 & 2.23 & 4.88 \\
\hline Module 2 & - & - & 2.83 \\
\hline Module 3 & 0.66 & 0.66 & 2.92 \\
\hline Module 4 & - & - & 2.73 \\
\hline
\end{tabular}

\section{DISCUSSION}

The defects observed in the PV modules prior to testing can be classified into four types. These include cracks, tire like patterns, completely dark regions, and shadowed regions (Fig.2 (a)). Tire like patterns indicate the regions of higher series resistance of the modules, while completely dark regions identify the regions which are electrically isolated because of the cracks. The pre-loading cracks in the cells originate as a result of stresses generated during cell manufacturing, module lamination and transportation. These cracks hinder the flow of electric current and thus lower the output power of the module. The orientation of these cracks with respect to the cell geometry determines how critical they are. Cracks parallel to the bus bars cause the complete isolation of the cell regions and are detrimental to the power output. In contrast to these, cracks diagonal to the bus bars are less crucial to the power output. Static wind loads degrade mechanical integrity of modules in two ways; by aiding in the propagation of existing cracks and initiating new cracks. EL images of the modules after the application of the load show that cracks were induced in the modules (Fig. 2-b and 3-b). The orientation of these cracks was found to be diagonal to the bus bars and hence were less damaging to the power output. This is confirmed by the results of solar flash testing.

Analysis of electrical performance of the PV modules was based on three important parameters as discussed above. Although cracks were observed in all the four modules, the peak power degraded for only two modules i.e. modules 1 and module 3 (see Table 2), due to the presence of greater number of cracks in these modules. Maximum percent power drop of $2.23 \%$ was observed in module 1; cracks in modules 2 and 4 were not significant and did not produce any notable power drop. The efficiency of PV modules, in particular photo to electricity conversion is generally $17-20 \%$. This efficiency depends on several factors such as type of solar cell, mechanical integrity of the module, reflectivity of glass, module manufacturing and conduction efficiency etc. Efficiencies of the modules prior to application of mechanical loads was $11.5-14.3 \%$. The drop in output power noted above caused a drop in efficiency for modules 1 and 3, while no change was observed in modules 2 and 4 . This is in agreement to a previous study [9], which also showed that the cracks parallel to the busbars are more detrimental and affect the power more adversely, while the cracks oriented diagonally to the busbar decrease the power only slightly.

Series resistance of a module arises from the resistance provided by the cells themselves, due to metallization (bus bars and fingers) and internal structural defects 
such as cracks. This resistance must be overcome in order to draw current from the cells. In other words, the measure of series resistance of a module is a direct measure of its internal defects and flaws. Average series resistance of the modules prior to testing was 734 milli-ohm which increased to 759 milli-ohm after undergoing the wind load test. This change was due to the generation of new cracks which resulted in an increased resistance in the path of current. Also notable in the results is that a change in series resistance was noted for all the four modules. Hence change in series resistance can be directly correlated with the number of cracks within the PV module. Mean increase in series resistance due to wind load was $3.37 \%$.

The large variation of quality observed amongst the PV panels from the same vendor shows that proper quality control and handling procedures have not been practiced. In general, a single panel is not installed by the end user, but a complete system comprising of multiple panels connected in series or parallel combination is used. The overall output of such a system is controlled by the panel producing the minimum power. Hence malfunctioning of even a single panel results in reduced output power. The current work highlights the inconsistencies in performance of the modules locally available in the Pakistani market. PV panel manufacturers and vendors should therefore be forced to follow standard manufacturing and handling methods to ensure high efficiencies throughout the life of PV panels.

\section{CONCLUSIONS}

Four commercially available mono-crystalline photovoltaic modules of $60 \mathrm{~W}$ rated power were subjected to a load of $2400 \mathrm{~Pa}$ simulating static wind load. EL imaging and solar flash testing of these samples was carried out before and after the application of load. The results show that wind load have the tendency to induce cracks in the PV modules, as well as propagate the existing cracks. Most of these induced cracks were oriented diagonally to the bus bars. The extent of mechanical degradation depends on the initial conditions of the modules: Less defective modules experience lesser degradation, while highly defective modules degrade to a higher extent. The mechanical degradation results in a decrease in electrical performance as reported by the results of solar flash testing. Three electrical parameters namely series resistance, efficiency and peak power output were analyzed. The results show that wind load on PV modules caused a $3.37 \%$ increase in mean series resistance, and $0.72 \%$ decrease in the average peak power output. Since the output of a PV system is controlled by the panel producing the lowest power, proper quality control procedures should be adopted by manufacturers and vendors to ensure consistent performance.

\section{REFERENCES}

1. https://www.studentenergy.org/posts/533-shalerenewables-and-the-new-energy-paradigm. [Last Accessed on 26th June 2016].

2. Awan M.M.A., Awan F.G., "Improvement of Maximum Power Point Tracking Perturb and Observe Algorithm for a Standalone Solar Photovoltaic System", Mehran University Research Journal of Engineering and Technology, Vol. 36, No. 3, pp. 501-510, 2017.

3. Pingel S., Zemen Y., Frank O., Geipel T., Berghold J., "Mechanical stability of solar cells within solar panels", Proceedings of the 24th European PV Solar Energy Conference and Exhibition, Hamburg, Germany, pp. 2459-3463, 2009.

4. Kajari-Schröder S., Kunze I., Köntges M., "Criticality of cracks in PV modules", Energy Procedia, Vol. 27, pp. 658-663, 2012.

5. Lee Y., Tay A. A. O., "Stress analysis of silicon wafer-based photovoltaic modules under IEC 61215 mechanical load test", in PV Asia Pacific Conference, 2012, Energy Procedia, Vol. 33, pp. 265-271, 2013.

6. Zarmai M.T., Ekere N.N., Oduoza C.F., Amalu E. H., "A review of interconnection technologies for improved crystalline silicon solar cell photovoltaic module assembly", Applied Energy, Vol. 154, pp. 173-182, 2015.

7. Ndiaye A., Charki A., Kobi A., Kebe C.M.F., Ndiaye P.A., Sambou V., "Degradation of silicon photovoltaic modules: A literature Review", Solar Energy, Vol. 96, pp. 140-151, 2016. 
8. Munoz M. A., Alonso-Garcia M.C., Vela N., Chenlo F., "Early degradation of silicon PV modules and guaranty conditions", Solar Energy, Vol. 85, pp. 2264-2274, 2011.

9. Sharma V., Chandel S.S., "Performance and degradation analysis for long term reliability of solar photovoltaic systems: A review", Renewable and Sustainable Energy Reviews, Vol. 27, pp. 753-767, 2013.

10. Köntges M., Kajari-Schröder S., Kunze I., Jahn U., "Crack statistics of crystalline silicon photovoltaic modules", Proceedings of the European Photovoltaic Solar Energy Conference and Exhibition, Hamburg, Germany, pp. 32903294, 2011.

11. Fuyuki T., "Luminoscopy: A versatile tool for the diagnosis of crystalline silicon solar cells utilizing electroluminescence", Proceedings of the 9th International Conference on Polycrystalline Semiconductors, POLYSE, 2006.
12. Measurement principles for terrestrial photovoltaic (PV) solar devices with reference spectral irradiance data, International ElectroTechnical Commission standard 60904-3, 2016.

13. Standard Test Methods for Determining Mechanical Integrity of Photovoltaic Modules, ASTM standard E1830-15, 2009.

14. Crystalline Silicon Terrestrial Photovoltaic (PV) Modules. Design Qualification and Type Approval IEC Central Office, Geneva, Switzerland, International Electro-Technical Commission standard 61215, 1987. 